\title{
Search for a Primary Isotopic Effect on the Magnetic Shielding of the Rubidium and Cadmium Isotopes
}

\author{
H. Krüger, O. Lutz, A. Nolle, A. Schwenk, and G. Stricker \\ Physikalisches Institut der Universität Tübingen \\ (Z. Naturforsch. 28 a, $484-486$ [1973] ; received 15 December 1972)
}

\begin{abstract}
The ratios of the $g_{\mathrm{I}}$-factors of ${ }^{85} \mathrm{Rb}$ and ${ }^{87} \mathrm{Rb}$ and of ${ }^{111} \mathrm{Cd}$ and ${ }^{113} \mathrm{Cd}$ have been measured in aqueous solutions of salts by the NMR method with high accuracy. A comparison with the same ratios measured by optical pumping techniques in free atoms shows agreement within the limits of error of $2.3 \cdot 10^{-6}$ in the case of rubidium and of $3 \cdot 10^{-7}$ in the case of cadmium: No difference in the magnetic shielding between the isotopes is observable.
\end{abstract}

\section{Introduction}

Very accurate ratios of the $g_{\mathrm{I}}$-factors of isotopic pairs must be available for evaluating small hyperfine structure anomalies ${ }^{1}$. Such ratios are usually measured by the nuclear magnetic resonance (NMR) method in an almost arbitrary chemical surrounding. Recently some papers have appeared, in which a "primary isotopic effect" on the chemical shift of the nuclei of an isotopic pair has been reported: Tupciauskas et al. ${ }^{2}$ found in some tin compounds differences of about $3 \cdot 10^{-6}$ between the ratios of $g_{\mathrm{I}}\left({ }^{119} \mathrm{Sn}\right) / g_{\mathrm{I}}\left({ }^{117} \mathrm{Sn}\right)$. There are also discrepancies of about $2 \cdot 10^{-6}$ in the ratios of $g_{\mathrm{I}}\left({ }^{15} \mathrm{~N}\right) / g_{\mathrm{I}}\left({ }^{14} \mathrm{~N}\right)$ measured in several nitrogen compounds by different authors ${ }^{3,4,5}$, all using the nuclear magnetic double resonance method as in the case of tin. Other authors found in similar measurements for ${ }^{35} \mathrm{Cl}$, ${ }^{37} \mathrm{Cl}\left(\right.$ see $\left.^{6}\right)$ and ${ }^{123} \mathrm{Te},{ }^{125} \mathrm{Te}\left(\right.$ see ${ }^{7}$ ) in some different chemical compounds agreement within $2 \cdot 10^{-7}$ for the ratios of $g_{\mathrm{I}}$-factors.

\section{Primary Isotopic Effect on the Magnetic Shielding}

The Larmor frequency $\omega_{\mathrm{L}}$ of a nucleus in a diamagnetic liquid in a magnetic field $H_{0}$ can be written as

$$
\omega_{\mathrm{L}}=\gamma H_{0}(1-\sigma)
$$

$\gamma=g_{\mathrm{I}}\left(\mu_{\mathrm{N}} / \hbar\right)$ is the gyromagnetic ratio, $\mu_{\mathrm{N}}$ is the nuclear magneton, $g_{\mathrm{I}}$ is the nuclear Landé- $g$-factor and $\sigma$ is the shielding constant.

If the shielding constant is not referred to the unpracticable bare nucleus but to the free atom, the

Reprint requests to Dr. O. Lutz, Physikalisches Institut der Universität Tübingen, D-7400 Tübingen, Gmelinstr. 6, Germany. following relation holds ${ }^{8}$ :

$$
\sigma^{*}=\left(\gamma_{\text {atom }}-\gamma_{\text {NMR }}\right) / \gamma_{\text {atom }} \text {. }
$$

YMAR is measured by an NMR experiment in a diamagnetic liquid and $\gamma_{\text {atom }}$ is measured using free atoms.

The shielding constant usually changes from a compound 1 to a compound 2, the difference $\sigma_{1}{ }^{*}-\sigma_{2}{ }^{*}=\delta$ is called the chemical shift.

The ratio of the Larmor frequencies of two isotopes $\mathrm{a}$ and $\mathrm{b}$ of the same element in the same magnetic field and in the same compound is

$\frac{\omega(\mathrm{a})}{\omega(\mathrm{b})}=\frac{\gamma(\mathrm{a})}{\gamma(\mathrm{b})} \cdot \frac{(1-\sigma(\mathrm{a}))}{(1-\sigma(\mathrm{b}))}=\frac{\gamma_{\text {atom }}(\mathrm{a})}{\gamma_{\text {atom }}(\mathrm{b})} \cdot \frac{\left(1-\sigma^{*}(\mathrm{a})\right)}{\left(1-\sigma^{*}(\mathrm{~b})\right)}$

If for two compounds having a chemical shift $\delta$ this ratio is found to be not constant, there must be an isotopic effect on the shielding constant:

$$
\sigma^{*}(\mathrm{a}) \neq \sigma^{*}(\mathrm{~b}) \text {. }
$$

The size of such an effect mentioned in the introduction seems to be surprisingly large.

A primary isotopic effect on the shielding constant might perhaps be caused by the differences between the masses and the magnetic moments of the nuclei of the two isotopes.

For searching for further primary isotopic effects we have measured the ratios of the $g_{\mathrm{I}}$-factors of the isotopic pairs ${ }^{85} \mathrm{Rb},{ }^{87} \mathrm{Rb}$ and ${ }^{111} \mathrm{Cd},{ }^{113} \mathrm{Cd}$ by the NMR-method. These pairs have been chosen, since the magnetic moments of the rubidium isotopes are very different and the chemical shifts of cadmium are very large ${ }^{8}$. Further, for these pairs accurate ratios of $g_{\mathrm{I}}$-factors measured by the optical pumping technique on free atoms are available ${ }^{9,10}$, which can be compared with those measured by the NMR method. An isotopic effect on the shielding constant 
ought to be easier to detect in the chosen cases since $\left|\sigma^{*}\right|$ is mostly larger than $|\delta|$; the appropriate shielding constants are known:

$\sigma^{*}\left(\mathrm{Rb}^{+}\right.$in $\mathrm{D}_{2} \mathrm{O}$ vs. free $\mathrm{Rb}$-atom $)$

$\sigma^{*}\left(\mathrm{Cd}^{++}\right.$in $\mathrm{H}_{2} \mathrm{O}$ vs. free $\mathrm{Cd}$-atom $)$

$$
=-2.11(2) \cdot 10^{-4} \quad\left(\text { Ref. }^{11}\right),
$$

$$
=-1.11(2) \cdot 10^{-3}\left(\text { Ref. }^{8}\right) \text {. }
$$

\section{Measurements of the Larmor Frequencies}

The measurement of the Larmor frequencies of ${ }^{85} \mathrm{Rb}$ and ${ }^{87} \mathrm{Rb}$ has been made by a cw-nuclear magnetic resonance spectrometer reported elsewhere ${ }^{12,13}$. The cadmium measurements were done with a Fourier transform NMR spectrometer ${ }^{14}$. The Larmor-frequencies of each pair ${ }^{85} \mathrm{Rb},{ }^{87} \mathrm{Rb}$ and ${ }^{111} \mathrm{Cd},{ }^{113} \mathrm{Cd}$ were measured alternately in the same probe and sample only by varying the radiofrequency. The magnetic field is held constant to $1 \cdot 10^{-7}$ with the aid of a ${ }^{7} \mathrm{Li}$ NMR probe ${ }^{15}$. Table 1 shows the experimental conditions.

The linewidths in the case of $\mathrm{Rb}$ are different because of the different quadrupole moments. The linewidths for the cadmium nuclei are due to the special technique, necessary for slowly relaxing nuclei with spin $1 / 2$ (see Ref. ${ }^{16}$ ).

The results are given in Table 2 .

The ratio of the cadmium isotopes was measured in two different samples, since we have found a very large difference between the Larmor frequencies in $\mathrm{CdCl}_{2}$-solutions and $\mathrm{Cd}\left(\mathrm{NO}_{3}\right)_{2}$-solutions, measured by ${ }^{111} \mathrm{Cd}$ NMR: the chemical shift between solution [2] and solution [3] is $\delta=1.773(4) \cdot 10^{-4}$, which is 6 times smaller than $\sigma^{*}\left(\mathrm{Cd}^{++}\right.$in $\mathrm{H}_{2} \mathrm{O}$ vs. free $\mathrm{Cd}$ atoms).
There are some other measurements of the ratios of the Larmor frequencies of the rubidium isotopes ${ }^{17}$ and the cadmium isotopes ${ }^{18,19}$, which all have less accuracy or no given error ${ }^{20}$. They are in agreement with our experiments within the given limits of error.

In Table 2 the results of the optical pumping experiments using free atoms are also given.

\section{Conclusions}

Within the limits of error no difference between the NMR and the optical pumping experiments is observable, though the shielding constants of the NMR samples are rather large. The chosen isotopic pairs are very favourable since the rubidium isotopes have very different nuclear magnetic moments and different nuclear spin. In the case of cadmium we have very large shielding constants and also large differences in the shielding constants for the two samples used. We conclude, that in these cases an isotopic effect on the shielding constant must be very small if there is one at all.

Therefore we remark, that the NMR method remains further a very simple and accurate method for measuring ratios of $g_{\mathrm{I}}$-factors of isotopes of the same element, which can be used in atomic physics.

Since the measurements mentioned in the introduction are all made by the nuclear magnetic double resonance method ${ }^{21}$, a direct measurement of the ratios of the Larmor frequencies of these isotopic pairs seems to be very useful for clearing the discrepancies. Some work has recently done for the three tin isotopes ${ }^{115} \mathrm{Sn},{ }^{117} \mathrm{Sn}$ and ${ }^{119} \mathrm{Sn}$ (see Ref. ${ }^{22}$ ).

\begin{tabular}{|c|c|c|c|c|c|c|c|}
\hline Nucleus & Spin & $\begin{array}{l}\text { approximate } \\
\text { Larmor } \\
\text { frequency } \\
\text { in } \mathrm{MHz}\end{array}$ & $\begin{array}{l}\text { Line- } \\
\text { width } \\
\mathrm{Hz}\end{array}$ & $\begin{array}{l}\text { measuring } \\
\text { time } \\
\text { minutes }\end{array}$ & & sample & $\begin{array}{l}\text { temperature } \\
\mathrm{K}\end{array}$ \\
\hline${ }^{85} \mathrm{Rb}$ & $5 / 2$ & 7.428 & 140 & 8 & [1] & $\begin{array}{l}\mathrm{RbCl} \text { in } \mathrm{D}_{2} \mathrm{O} \\
5,99 \text { molal }\end{array}$ & $296 \pm 2$ \\
\hline${ }^{87} \mathrm{Rb}$ & $3 / 2$ & 25.175 & 230 & 3,5 & & & \\
\hline${ }^{111} \mathrm{Cd}$ & $1 / 2$ & 16.314 & $70 *$ & 12 & {$[2]$} & $\begin{array}{l}\mathrm{CdCl}_{2} \text { in } \mathrm{H}_{2} \mathrm{O} \\
4,82 \text { molal }\end{array}$ & \\
\hline${ }^{113} \mathrm{Cd}$ & $1 / 2$ & 17.066 & $70 *$ & 12 & [3] & 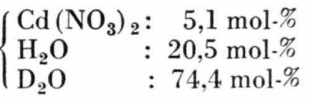 & $303 \pm 3$ \\
\hline
\end{tabular}

Table 1. Experimental conditions employed for recording the rubidium and cadmium resonances at a field of 1,807 Tesla.

\footnotetext{
* due to QFT-technique ${ }^{16}$.
} 
Table 2. Ratios of the Larmor frequencies of this work and of the optical pumping experiments (OP). Since LEDUC and LEHMANN ${ }^{10}$ gave as an error two times the standard deviation

$$
s=\sqrt{\sum_{i=1}^{N}\left(\bar{x}-x_{i}\right)^{2}} /(N-1)
$$

within which limit most of their measured ratios are situated, we have given our measurements also with this error.

\begin{tabular}{|c|c|c|c|c|c|c|}
\hline $\begin{array}{l}\text { Isotopic } \\
\text { pairs }\end{array}$ & $\begin{array}{l}\text { Number } \\
\text { of ratios }\end{array}$ & $\begin{array}{l}\text { Ratio of the Larmor } \\
\text { frequencies }\end{array}$ & error & method & sample & Reference \\
\hline${ }^{85} \mathrm{Rb}, \quad{ }^{87} \mathrm{Rb}$ & 29 & $0.2950736(3)$ & $\begin{array}{l}2 \text { times } \\
\text { standard } \\
\text { deviation }\end{array}$ & NMR & [1] of table 1 & this work \\
\hline${ }^{85} \mathrm{Rb},{ }^{87} \mathrm{Rb}$ & 32 & $0.2950736(7) *$ & $\begin{array}{l}\text { weighted } \\
\text { rms }\end{array}$ & $\mathrm{OP}$ & free atoms & (9) \\
\hline${ }^{111} \mathrm{Cd},{ }^{113} \mathrm{Cd}$ & 31 & $0.95594609(24)$ & $\begin{array}{l}2 \text { times } \\
\text { standard } \\
\text { deviation }\end{array}$ & NMR & [2] of table 1 & this work \\
\hline${ }^{111} \mathrm{Cd},{ }^{113} \mathrm{Cd}$ & 33 & $0.95594603(26)$ & $\begin{array}{l}2 \text { times } \\
\text { standard } \\
\text { deviation }\end{array}$ & NMR & [3] of table 1 & this work \\
\hline${ }^{111} \mathrm{Cd},{ }^{113} \mathrm{Cd}$ & $\approx 100$ & $0.95594618(18)$ & $\begin{array}{l}2 \text { times } \\
\text { standard } \\
\text { deviation }\end{array}$ & $\mathrm{OP}$ & free atoms & (10) \\
\hline
\end{tabular}

* Calculated from the given $g_{I}$-factors, which are measured by the doublet method, giving just the resonance frequency of the shielded nucleus in the applied magnetic field ${ }^{9}$.

\section{Acknowledgement}

We thank the Deutsche Forschungsgemeinschaft for the financial support of this work.

1 H. Krüger, O. Lutz, A. Nolle, and A. Uhl, Z. Naturforsch. 27 a, 173 [1972].

2 A. Tupciauskas, N. M.Sergeyev, and Yu. A. Ustynyku, Mol. Phys. 21, 179 [1971].

3 J. D. Baldeschwieler, J. Chem. Phys. 36, 152 [1962].

4 R. PRICE in Progr. NMR Spectrosc. 6, 119 [1971], ed. by E. W. Randall and D. G. Gillies.

5 E. D. Becker, R. B. Bradley, and T. Axenrod, J. Magn. Res. 4, 136 [1971].

6 O. Lutz, Phys. Letters 31 A, 528 [1970].

7 G. Pfister and H. Dreeskamp, Ber. Bunsenges. Physikal. Chem. 73, 654 [1969].

8 to be published.

9 C. W. White, W. M. Hughes, G. S. Hayne, and H. G. Robinson, Phys. Rev. 174, 23 [1968].

10 M. Leduc and J. C. Lehmann, C. R. Acad. Sci. Paris, 262 B, 736 [1966].
11 O. Lutz and A. Nolle, Z. Naturforsch. 27 a, 1577 [1972].

12 O. LuTZ, Z. Naturforsch. 23 a, 1202 [1968].

13 J. Blaser, O. Lutz, and W. Steinkilberg, Z. Naturforsch. 27 a, 72 [1972].

14 to be published.

15 J. Kaufmann and A. Schwenk, Z. Angew. Phys. 21, 527 [1966].

16 A. Schwenk, J. Magn. Res. 5, 376 [1971].

17 W. E. Blumberg, J. Eisinger, and M. P. Klein, Phys. Rev. 124, 206 [1961].

18 W. G. Proctor, Phys. Rev. 79, 35 [1950].

19 M. P. Klein and J. S. Waugh, Phys. Rev. 116, 960 [1959].

20 K. Hildenbrand and H. Dreeskamp, Z. Phys. Chem. 69, 171 [1970].

21 W. McFarlane, Ann. Rep. NMR Spectrosc. 5 A 353 [1972]

22 to be published. 